\title{
Ceftriaxone-induced up-regulation of cortical and striatal GLT1 in the R6/2 model of Huntington's disease
}

\author{
Youssef Sari ${ }^{1,2,3}$, Anne L Prieto ${ }^{1,2}$, Scott J Barton ${ }^{1,2}$, Benjamin R Miller ${ }^{1,2,4}$, George V Rebec ${ }^{1,2^{*}}$
}

\begin{abstract}
Background: Huntington's disease (HD) is an inherited neurodegenerative disorder characterized by cortico-striatal dysfunction and loss of glutamate uptake. At 7 weeks of age, R6/2 mice, which model an aggressive form of juvenile $H D$, show a glutamate-uptake deficit in striatum that can be reversed by treatment with ceftriaxone, a $\beta$-lactam antibiotic that increases GLT1 expression. Only at advanced ages (> 11 weeks), however, do R6/2 mice show an actual loss of striatal GLT1. Here, we tested whether ceftriaxone can reverse the decline in GLT1 expression that occurs in older R6/2s.
\end{abstract}

Results: Western blots were used to assess GLT1 expression in both striatum and cerebral cortex in R6/2 and corresponding wild-type (WT) mice at 9 and 13 weeks of age. Mice were euthanized for immunoblotting $24 \mathrm{hr}$ after five consecutive days of once daily injections (ip) of ceftriaxone $(200 \mathrm{mg} / \mathrm{kg})$ or saline vehicle. Despite a significant GLT1 reduction in saline-treated R6/2 mice relative to $W T$ at 13 , but not 9, weeks of age, ceftriaxone treatment increased cortical and striatal GLT1 expression relative to saline in all tested mice.

Conclusions: The ability of ceftriaxone to up-regulate GLT1 in R6/2 mice at an age when GLT1 expression is significantly reduced suggests that the mechanism for increasing GLT1 expression is still functional. Thus, ceftriaxone could be effective in modulating glutamate transmission even in late-stage HD.

\section{Background}

Ample evidence indicates that the neuropathology associated with Huntington's disease (HD), an autosomal dominant condition characterized by behavioral, cognitive, and physical deterioration, involves the dysregulation of glutamate, an excitatory amino acid [1-4]. In fact, a decline in glutamate removal has been observed in the brains of transgenic mouse models of HD [5-7] as well as HD patients post-mortem [8]. Loss of glutamate uptake leads to accumulation of extracellular glutamate, making neurons vulnerable to excitotoxicity. Interestingly, GLT1, a protein expressed primarily on glial cells and responsible for the removal of most extracellular glutamate $[9,10]$, appears to be dysfunctional in HD mouse models $[5,6,11]$. We recently reported that the deficit in glutamate uptake in the commonly used R6/2 model at 8 weeks of age can be reversed following

\footnotetext{
* Correspondence: rebec@indiana.edu

'Program in Neuroscience, Indiana University, 1101 East 10th Street, Bloomington, IN, USA
}

treatment with ceftriaxone [7], a beta-lactam antibiotic that elevates the level of GLT1 without altering the expression of other glutamate transporters [12]. By upregulating GLT1, ceftriaxone appears to overcome a functional GLT1 deficit since the level of protein does not decline until R6/2 mice exceed 11 weeks of age $[5,6,11]$. Here, we determined if ceftriaxone could increase GLT1 expression even in R6/2 mice that have a deficit in GLT1 production. We focused on cerebral cortex and striatum, two forebrain regions that show the greatest HD neuropathology [13,14]. Our results suggest that the cellular machinery by which ceftriaxone increases cortical and striatal GLT1 expression is still intact even in late-stage HD.

\section{Methods \\ Animals}

Male transgenic R6/2 mice (B6CBA-TgN[HDexon1] $62 \mathrm{Gpb}$ ) and wild-type (WT) controls were obtained from The Jackson Laboratories (Bar Harbor, ME) at 6

\section{C) Biomed Central}


weeks of age. All mice were housed individually in the departmental animal colony under standard conditions (12 hr light/dark cycle with lights on at 07:00 AM) with access to food and water ad libitum. Both the housing and experimental use of animals followed the National Institutes of Health guidelines and were approved by the Institutional Animal Care and Use Committee at Indiana University Bloomington.

\section{Genotype and CAG repeat length}

We used PCR for genotyping and characterizing the CAG repeat length as previously reported [7]. Our R6/2 mice had $121 \pm 1.8$ (mean \pm SEM) CAG repeats, which is within the range for developing the HD behavioral phenotype [15].

\section{Treatment protocol}

R6/2 and WT mice at either 8 or 12 weeks of age were weighed and injected ip with $200 \mathrm{mg} / \mathrm{kg}$ ceftriaxone (Sigma, St. Louis, MO) or an equal volume of saline once daily for 5 consecutive days. Twenty-four hours after the last injection, when the mice had reached 9 or 13 weeks of age, the animals were decapitated. Their brains were removed, and cerebral cortex and striatum from both hemispheres were dissected and frozen for immunoblotting.

\section{Western blot}

Western blots for GLT1 detection were performed as previously described $[7,16]$. In brief, extracted proteins were separated in 4-20\% glycine gel (Invitrogen). The membranes were blocked in $3 \%$ milk in TBST $(50 \mathrm{mM}$ Tris $\mathrm{HCl} ; 150 \mathrm{mM} \mathrm{NaCl}, \mathrm{pH} 7.4 ; 0.1 \%$ Tween20) for 30 min at room temperature. The membranes were then incubated with guinea pig anti-GLT1 antibody (Millipore Bioscience Research Reagents) at 1:5,000 dilution in blocking buffer at $4^{\circ} \mathrm{C}$. After washing and blocking, the membranes were incubated with horseradish peroxidase (HRP)-labeled anti-guinea pig secondary antibody (1:10,000 dilution) in the blocking buffer. Protein loading was normalized using $\beta$-tubulin immunoblotting as a loading control. Chemiluminescent detection of HRP (SuperSignal West Pico; Pierce) was followed by exposure of the membranes to a Kodak BioMax MR film (Thermo Fisher Scientific). The films were developed on an SRX-101A machine. Digitized images of immunoreactive proteins were quantified using an MCID system. The data are reported as percentage ratios of GLT1/ $\beta$ tubulin.

\section{Statistical analysis}

Data were analyzed by means of a two-way analysis of variance (ANOVA) and Bonferroni post hoc tests. All
Table 1 Body weight

\begin{tabular}{ccccc}
\hline Age & WTs & R6/2s & WTc & R6/2c \\
\hline 9-week & $27.53 \pm 1.18$ & $26.52 \pm 1.02$ & $27.27 \pm 1.02$ & $28.06 \pm 1.18$ \\
& $(N=4)$ & $(\mathrm{N}=4)$ & $(\mathrm{N}=4)$ & $(\mathrm{N}=4)$ \\
13-week & $34.3 \pm 2.75$ & $* 26.78 \pm 1.69$ & $33.00 \pm 0.98$ & $* 24.52 \pm 2.33$ \\
& $(\mathrm{~N}=5)$ & $(\mathrm{N}=5)$ & $(\mathrm{N}=5)$ & $(\mathrm{N}=5)$ \\
\hline
\end{tabular}

Data are presented as mean body weight $(\mathrm{g}) \pm \mathrm{SEM}$. ${ }^{*} P<0.001, \mathrm{HD}$ compared to their respective WT. Abbreviations: WTs and R6/2s indicate saline treatment, and WTc and R6/2c indicate ceftriaxone treatment. $\mathrm{N}$ refers to number of animals per group.

statistical tests required a level of significance of at least $P<0.05$.

\section{Results}

\section{Body weights}

Table 1 shows the mean body weight of all groups on the last day of treatment. No significant differences were found between genotype (WT and R6/2) or treatment group (ceftriaxone and saline) at 9 weeks of age. Regardless of treatment, however, there was a significant reduction in body weight in $\mathrm{R} 6 / 2$ relative to WT mice $(P<0.001)$ at 13 weeks of age, which supports previous evidence that at this age R6/2 mice are strongly symptomatic [17].

\section{Effects of ceftriaxone treatment in cortical and striatal GLT1 expression}

Although saline-treated R6/2s showed no loss of either cortical or striatal GLT1 relative to WT at 9 weeks of age (Figure 1), there was a marked reduction in both brain regions in similarly treated 13-week-old R6/2s (Figure 2). Quantitative analysis of this age group revealed significant genotypic differences in GLT1 expression in both cerebral cortex $(P<0.01)$ and striatum $(P<0.03)$. Despite the loss of GLT1 in older R6/2s, these animals showed the same response to ceftriaxone as the younger R6/2s and both WT age groups. Thus, WT and R6/2 mice at either 9 (Figure 1) or 13 weeks of age (Figure 2) responded to ceftriaxone with an increase in cortical and striatal GLT1 expression relative to saline. Quantitative analysis revealed a significant effect of ceftriaxone in both brain regions at 9 and 13 weeks of age $(P<0.0001$ in each case).

\section{Discussion}

Our results not only confirm the ability of ceftriaxone to elevate GLT1 expression in cortex and striatum of R6/2 mice, but show that this effect still occurs even after GLT1 levels begin to decline when these mice are 13 weeks of age and severely symptomatic. Thus, it appears that the cellular machinery underlying the ceftriaxoneinduced increase in GLT1 expression is operative in late-stage HD. 
A

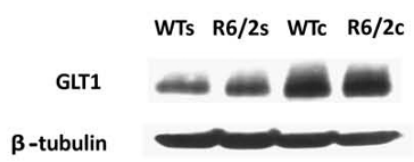

C

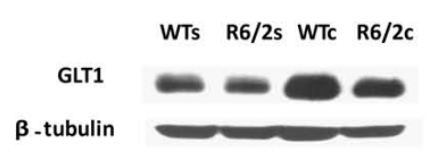

B

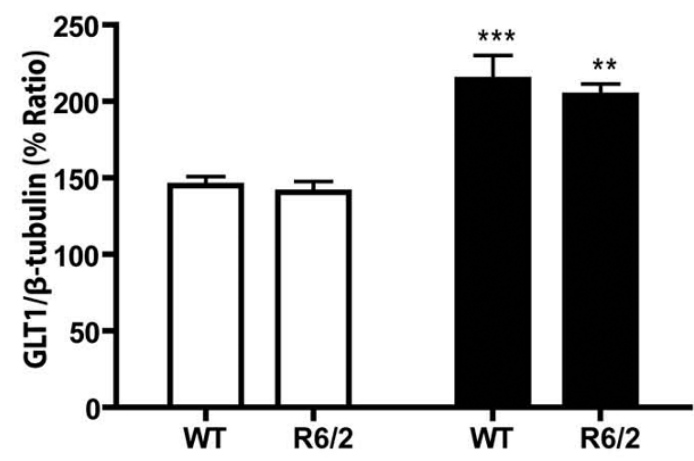

D

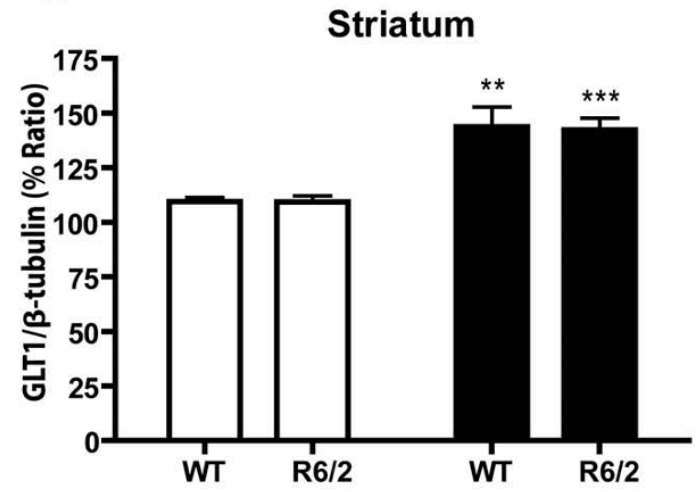

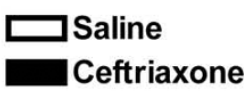

Ceftriaxone

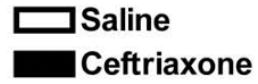

Figure 1 Effects of ceftriaxone on GLT1 expression in cerebral cortex and striatum at 9 weeks of age. Immunoblots (A, C) and quantitative analysis (B, D) of the percentage ratio of GLT1/ $\beta$-tubulin in cerebral cortex and striatum, respectively $\left(^{* * *} P<0.001\right.$ and $* * P<0.01$ relative to corresponding saline group). Error bars indicate SEM. ( $\mathrm{N}=4$ for each group).

Although the mechanism by which ceftriaxone increases GLT1 expression is not clear, there is support for activation of nuclear factor-kappa B (NF-kB), a transcription factor that plays a role in regulating immune responses and cell survival [18]. Translocation of the NF-kB complex to the cell nucleus appears to be critical for the action of ceftriaxone [19], and our results suggest that this mechanism is intact in both cortex and striatum of R6/2 mice regardless of age. Even before the decline in GLT1 expression, moreover, 8-week-old R6/2 mice have a deficit in glutamate uptake, which is reversed by ceftriaxone treatment [7]. Although there is no GLT1 protein deficit at this age, mRNA levels are in decline [6] and glutamate uptake is reduced [7], suggesting a loss of transporter function well in advance of protein down-regulation. Thus, ceftriaxone is capable of overcoming a deficit in GLT1 function. It is interesting in this regard that palmitoylation, a process by which proteins are inserted into cellular membranes [20], is reduced in HD mice, including palmitoylation of GLT1 [21]. Whether ceftriaxone increases GLT1 palmitoylation is the focus of ongoing research.
It is unlikely that other glutamate transporters can account for a ceftriaxone-induced increase in glutamate uptake since ceftriaxone acts selectively on GLT1 [12]. It also is unlikely that loss of other glutamate transporters can account for the decline in uptake since neither mRNA nor protein levels are altered for GLAST and EAAC1 in HD models even at ages when the behavioral phenotype is severe [6]. Post-mortem analysis of HD patients, moreover, shows a selective decline in GLT1 mRNA expression [22] as well as a loss of glutamate uptake [8]. Nevertheless, we cannot rule out the possibility that ceftriaxone has other actions that may indirectly impact glutamate transmission, including a change in dopamine or GABA dynamics. Although an antibiotic action of ceftriaxone is unlikely in that none of our animals showed signs of sepsis, it would be useful in follow-up studies to determine if non-antibiotics that also up-regulate GLT1, such as GPI-1046 [23], mimic the effects of ceftriaxone in R6/2 mice.

Increasing GLT1 expression may become an effective HD treatment strategy in that the up-regulation of GLT1 induced by ceftriaxone significantly improves the 


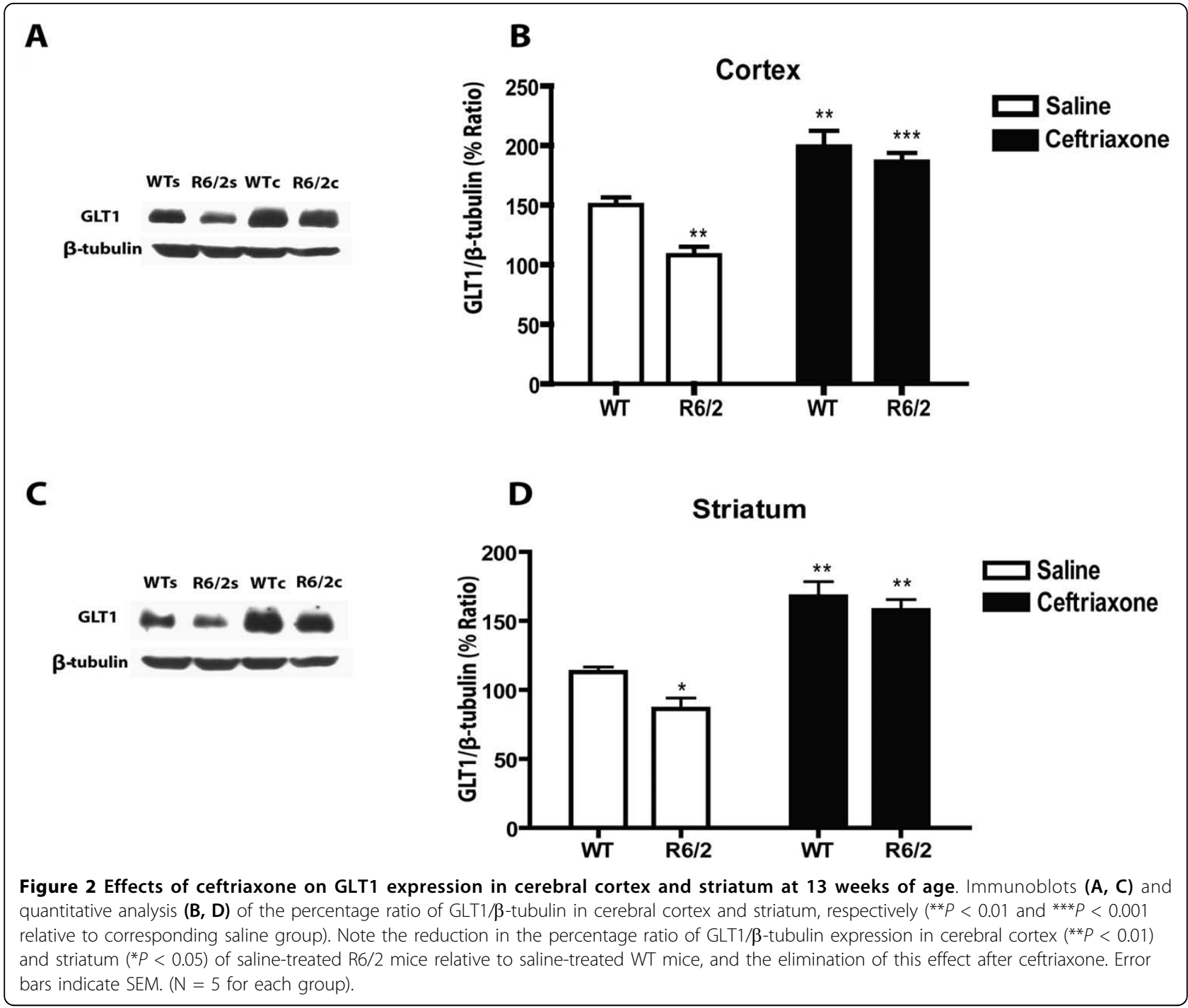

behavioral phenotype in 8-week-old R6/2 mice [7]. It is unlikely that starting ceftriaxone treatment in 13-weekold R6/2s will result in behavioral improvement given the stage of disease progression in these animals, and in fact, we found that ceftriaxone failed to reverse the decline in body weight, which is evident in R6/2s at this age. But our results suggest that the increase in GLT1 expression that occurs when ceftriaxone treatment is begun earlier will continue to occur even in late-stage HD. Thus, GLT1 expression is likely to be an effective therapeutic target over a relatively long time course.

Glutamate dysregulation, including a possible decline in GLT1 activity, may play a role in several neurodegenerative diseases [5,24]. In fact, a phase III clinical trial of ceftriaxone for treatment of amyotrophic lateral sclerosis (ALS) is already underway (for review see [25]). The dose required to increase GLT1 in mice produces comparable levels of ceftriaxone in the central nervous system of patients undergoing treatment for meningitis (0.3-6 $\mu \mathrm{mol} / \mathrm{L})$ [26], indicating that our treatment protocol is within normal limits for this drug. Nevertheless, it is interesting that ceftriaxone increased cortical and striatal GLT1 expression in both R6/2 and WT mice. WT mice, however, show no discernable behavioral consequences [7], suggesting that mechanisms are in place to compensate for increased glutamate removal. Whether HD mice lack these mechanisms or simply benefit from an increased rate of glutamate uptake remains to be determined. It appears that within limits increased GLT1 expression is not a problem, but decreased expression, which occurs in HD, is.

\section{Conclusions}

Ceftriaxone treatment enhances GLT1 expression in cerebral cortex and striatum of R6/2 mice at 13 weeks of age when endogenous GLT1 levels decline. These 
data suggest that the mechanism for increasing GLT1 expression is still functional even in late stage HD.

\section{Acknowledgements}

This research was supported by NINDS (R01 NS35663; F31 NS064791) and the METACyt Initiative of Indiana University, which is funded, in part, through a major grant from the Lilly Endowment, Inc. The authors would like to thank Makiko Sakai for technical contributions and Faye Caylor for administrative assistance.

\section{Author details}

'Program in Neuroscience, Indiana University, 1101 East 10th Street, Bloomington, IN, USA. ${ }^{2}$ Department of Psychological and Brain Sciences, Indiana University, 1101 East 10th Street, Bloomington, IN, USA. ${ }^{3}$ University of Toledo, College of Pharmacy, Department of Pharmacology, Health Science Campus, 3000 Arlington Avenue, Toledo, OH 43606, USA. ${ }^{4}$ University of Texas Southwestern Medical School, Department of Physiology. 5323 Harry Hines Boulevard, Dallas, TX 75390, USA.

\section{Authors' contributions}

YS participated in study design and conceptualization, collected and analyzed data, helped with data interpretation, and drafted the manuscript. ALP helped with data collection, analysis, and interpretation. SJB performed statistical analyses and genotyping, and helped with data interpretation. BRM participated in study design, and helped with data collection and analysis. GVR conceptualized and designed the study, and revised the manuscript for intellectual content. All authors read and approved the final manuscript.

\section{Competing interests}

The authors declare that they have no competing interests.

Received: 24 May 2010 Accepted: 27 July 2010 Published: 27 July 2010

\section{References}

1. DiFiglia M: Excitotoxic injury of the neostriatum: a model for Huntington's disease. Trends Neurosci 1990, 13(7):286-289.

2. Fonnum F, Storm-Mathisen J, Divac I: Biochemical evidence for glutamate as neurotransmitter in corticostriatal and corticothalamic fibres in rat brain. Neuroscience 1981, 6(5):863-873.

3. Harper PS: Huntington's Disease. W.B. Saunders London, 21996.

4. Ross CA: Polyglutamine pathogenesis: emergence of unifying mechanisms for Huntington's disease and related disorders. Neuron 2002, 35(5):819-822.

5. Behrens PF, Franz P, Woodman B, Lindenberg KS, Landwehrmeyer GB: Impaired glutamate transport and glutamate-glutamine cycling: downstream effects of the Huntington mutation. Brain 2002, 125(Pt 8):1908-1922.

6. Lievens JC, Woodman B, Mahal A, Spasic-Boscovic O, Samuel D, KerkerianLe Goff L, Bates GP: Impaired glutamate uptake in the R6 Huntington's disease transgenic mice. Neurobiol Dis 2001, 8(5):807-821.

7. Miller BR, Dorner JL, Shou M, Sari Y, Barton SJ, Sengelaub DR, Kennedy RT, Rebec GV: Up-regulation of GLT1 expression increases glutamate uptake and attenuates the Huntington's disease phenotype in the R6/2 mouse. Neuroscience 2008, 153(1):329-337.

8. Hassel B, Tessler S, Faull RL, Emson PC: Glutamate uptake is reduced in prefrontal cortex in Huntington's disease. Neurochem Res 2008, 33(2):232-237.

9. Danbolt NC: Glutamate uptake. Prog Neurobiol 2001, 65(1):1-105.

10. Robinson MB: The family of sodium-dependent glutamate transporters: a focus on the GLT-1/EAAT2 subtype. Neurochem Int 1998, 33(6):479-491.

11. Estrada-Sanchez AM, Montiel T, Segovia J, Massieu L: Glutamate toxicity in the striatum of the R6/2 Huntington's disease transgenic mice is agedependent and correlates with decreased levels of glutamate transporters. Neurobiol Dis 2009, 34(1):78-86.

12. Rothstein JD, Patel S, Regan MR, Haenggeli C, Huang YH, Bergles DE, Jin L, Dykes Hoberg M, Vidensky S, Chung DS, Toan SV, Bruijn LI, Su ZZ, Gupta P, Fisher PB: Beta-lactam antibiotics offer neuroprotection by increasing glutamate transporter expression. Nature 2005, 433(7021):73-77.
13. Cepeda C, Wu N, Andre VM, Cummings DM, Levine MS: The corticostriatal pathway in Huntington's disease. Prog Neurobiol 2007, 81(5-6):253-271.

14. Walker AG, Miller BR, Fritsch JN, Barton SJ, Rebec GV: Altered information processing in the prefrontal cortex of Huntington's disease mouse models. J Neurosci 2008, 28(36):8973-8982.

15. Mangiarini L, Sathasivam K, Seller M, Cozens B, Harper A, Hetherington C, Lawton M, Trottier Y, Lehrach H, Davies SW, Bates GP: Exon 1 of the HD gene with an expanded CAG repeat is sufficient to cause a progressive neurological phenotype in transgenic mice. Cell 1996, 87(3):493-506.

16. Sari Y, Smith KD, Ali PK, Rebec GV: Upregulation of GLT1 attenuates cueinduced reinstatement of cocaine-seeking behavior in rats. J Neurosci 2009, 29(29):9239-9243.

17. Carter RJ, Lione LA, Humby T, Mangiarini L, Mahal A, Bates GP, Dunnett SB, Morton AJ: Characterization of progressive motor deficits in mice transgenic for the human Huntington's disease mutation. J Neurosci 1999, 19(8):3248-3257.

18. Karin M: Nuclear factor-kappaB in cancer development and progression. Nature 2006, 441(7092):431-436.

19. Lee SG, Su ZZ, Emdad L, Gupta P, Sarkar D, Borjabad A, Volsky DJ, Fisher PB: Mechanism of ceftriaxone induction of excitatory amino Acid transporter-2 expression and glutamate uptake in primary human astrocytes. J Biol Chem 2008, 283(19):13116-13123.

20. Huang K, El-Husseini A: Modulation of neuronal protein trafficking and function by palmitoylation. Curr Opin Neurobiol 2005, 15(5):527-535.

21. Huang K, Kang MH, Askew C, Kang R, Sanders SS, Wan J, Davis NG, Hayden MR: Palmitoylation and function of Glial Glutamate Transporter-1 is reduced in the YAC128 mouse model of Huntington disease. Neurobiology of Disease.

22. Arzberger T, Krampfl K, Leimgruber $\mathrm{S}$, Weindl A: Changes of NMDA receptor subunit (NR1, NR2B) and glutamate transporter (GLT1) mRNA expression in Huntington's disease-an in situ hybridization study. $J$ Neuropathol Exp Neurol 1997, 56(4):440-454.

23. Ganel R, Ho T, Maragakis NJ, Jackson M, Steiner JP, Rothstein JD: Selective up-regulation of the glial Na+-dependent glutamate transporter GLT1 by a neuroimmunophilin ligand results in neuroprotection. Neurobiol Dis 2006, 21(3):556-567.

24. Maragakis NJ, Rothstein JD: Glutamate transporters in neurologic disease. Arch Neurol 2001, 58(3):365-370.

25. Traynor BJ, Bruijn L, Conwit R, Beal F, O'Neill G, Fagan SC, Cudkowicz ME: Neuroprotective agents for clinical trials in ALS: a systematic assessment. Neurology 2006, 67(1):20-27.

26. Nau R, Prange HW, Muth P, Mahr G, Menck S, Kolenda H, Sorgel F: Passage of cefotaxime and ceftriaxone into cerebrospinal fluid of patients with uninflamed meninges. Antimicrob Agents Chemother 1993, 37(7):1518-1524.

doi:10.1186/1423-0127-17-62

Cite this article as: Sari et al: Ceftriaxone-induced up-regulation of cortical and striatal GLT1 in the R6/2 model of Huntington's disease. Journal of Biomedical Science 2010 17:62.

\section{Submit your next manuscript to BioMed Central and take full advantage of:}

- Convenient online submission

- Thorough peer review

- No space constraints or color figure charges

- Immediate publication on acceptance

- Inclusion in PubMed, CAS, Scopus and Google Scholar

- Research which is freely available for redistribution
C Biomed Central 